
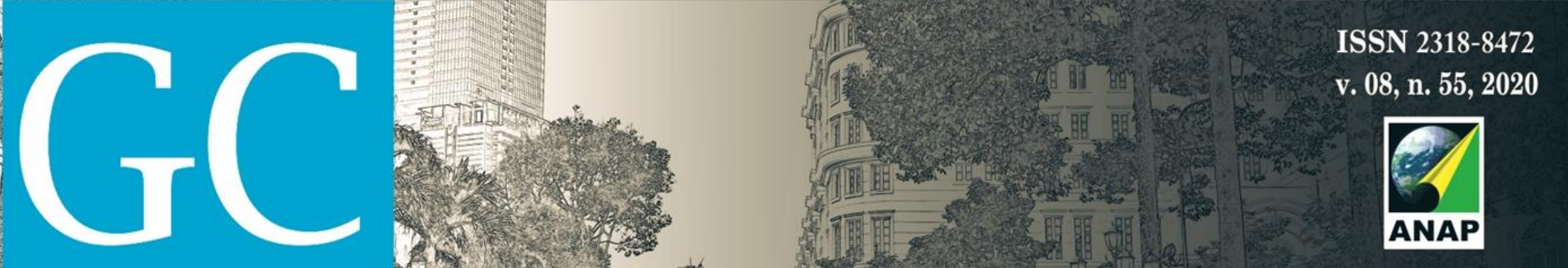

Revista Nacional de

Gerenciamento de Cidades

\title{
Política Pública em Habitação Social pós Estatuto da Cidade: análise da provisão da moradia do município de Vitória/ES, Brasil
}

Public Policy on Social Habitation after the City Statute: analysis of home provision in the city of Vitória / ES, Brazil

Política pública sobre vivienda social después del Estatuto de la ciudad: análisis de la provisión de viviendas en la ciudad de Vitória / ES, Brasil

\section{Andreia Fernandes Muniz}

Doutoranda do Programa de Pós-Graduação em Geografia - PPGG, UFES, Brasil

Professora do Curso de Arquitetura e Urbanismo, UVV, Brasil afernandesmuniz@gmail.com

\section{Eneida Maria Souza Mendonça}

Professora Doutora do Programa de Pós-Graduação em Geografia - PPGG e do Programa de Pós-Graduação em Arquitetura e Urbanismo - PPGAU, UFES, Brasil

eneidamendonca@gmail.com 


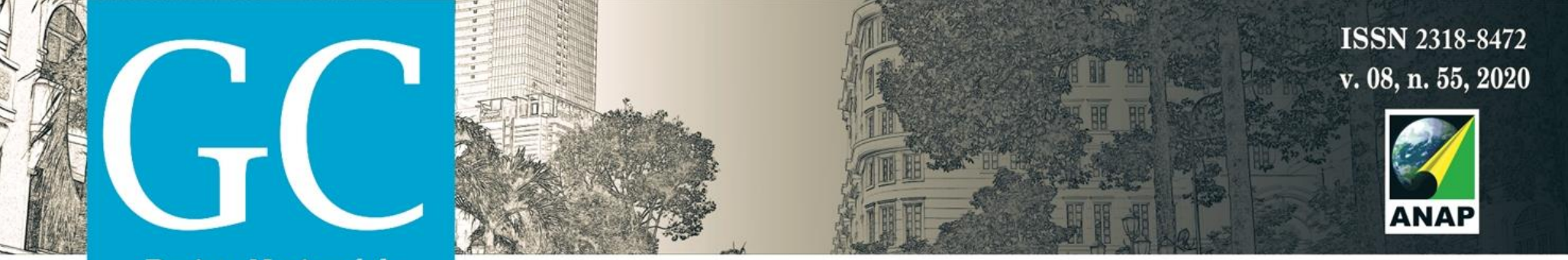

Revista Nacional de

Gerenciamento de Cidades

\section{RESUMO}

A Constituição Federal (1988) e o Estatuto da Cidade (2001), pautados na descentralização e valorização do poder local na implementação de políticas públicas, condicionaram ao ente municipal a responsabilidade de elaboração de metas e estratégias que visem resolver problemas no âmbito de seu território, especialmente os relacionados à disputa pelo direito à cidade, o que engloba a moradia. Diante da importância da atuação dos municípios na redução do déficit habitacional no país, este trabalho busca investigar, analisar e discutir as estratégias, programas, projetos, ações e investimentos da Política Habitacional do município de Vitória, capital do estado do Espírito Santo. A metodologia englobou pesquisa e análise bibliográfica e documental sobre conceitos, programas e recursos financeiros relacionados à provisão da moradia. Os resultados demonstram que o município, com aproximadamente 6.350 famílias em situação de déficit habitacional, tem buscado viabilizar o acesso à moradia social através da construção de novas unidades, melhorias habitacionais, auxílio aluguel, bônus moradia e urbanização de assentamentos precários. No entanto, a reabilitação de edifícios na região central e histórica da capital não tem sido prioridade e nem vista como alternativa eficiente para resolver a demanda habitacional. Além disso, os recursos previstos para habitação na dotação orçamentária representam percentual inferior a $5 \%$ da receita municipal, com valores reduzidos nos últimos quatro anos.

PALAVRAS-CHAVE: Habitação social. Política Pública. Política habitacional.

\section{ABSTRACT}

The Brazilian Constitution (1988) and the City Statute (2001), based on the decentralization and valorization of local autonomy in the implementation of public policies, attributed to the city hall the responsibility of elaborating goals and strategies to solve problems within its territory, mainly those related to the dispute for the right to the city, which includes housing. Considering the role of the city halls in reducing the housing deficit in Brazil, this paper investigates, analyzes and discusses the strategies, programs, projects, actions and investments of Vitória City, capital of the state of Espirito Santo, in its housing policy. The methodology included bibliographic and documentary research and analysis on concepts, programs and financial resources related to housing provision. The results show that the Vitória/ES City, with approximately 6,350 families in housing shortage, has sought to enable access to social housing through the construction of new buildings, housing improvements, financial assistance to rent houses, housing bonus and urbanization of precarious settlements. However, building rehabilitation in central and historical part of the capital has not been a priority nor seen as an efficient alternative to solve the housing demand. In addition, the resources provided for housing in the city budget represent less than 5\% of municipal revenue, with values reduced in the last four years.

Key-words: Social habitation. Public policy. Housing policy.

\section{Resumen}

La Constitución brasileña (1988) y su Estatuto de la ciudad (2001), basados en la descentralización y valorización de la autonomía local en la implementación de políticas públicas, atribuyen al ayuntamiento la responsabilidad de elaborar objetivos y estrategias para resolver problemas dentro de su territorio, principalmente los relacionados con la disputa por el derecho a la ciudad, que incluye la vivienda. Considerando el papel de los ayuntamientos en la reducción del déficit de vivienda en Brasil, este artículo investiga, analiza y discute las estrategias, programas, proyectos, acciones e inversiones de la ciudad de Vitória, capital del estado de Espírito Santo, en su política de vivienda. La metodología incluyó investigación y análisis bibliográfico y documental sobre conceptos, programas y recursos financieros relacionados con la provisión de viviendas. Los resultados muestran que la ciudad de Vitória / ES, con aproximadamente 6.350 familias en situación de déficit habitacional, ha tratado de permitir el acceso a viviendas sociales a través de la construcción de nuevos edificios, mejoras de viviendas, asistencia financiera para alquilar casas, bonificación de viviendas y urbanización de asentamientos precarios. Sin embargo, la rehabilitación de edificios en la parte central e histórica de la capital no ha sido una prioridad ni vista como una alternativa eficiente para resolver la demanda de viviendas. Además, los recursos provistos para vivienda en el presupuesto de la ciudad representan menos del $5 \%$ de los ingresos municipales, con valores reducidos en los últimos cuatro años.

Palabras clave: habitación social. Política pública. Política de vivienda. 


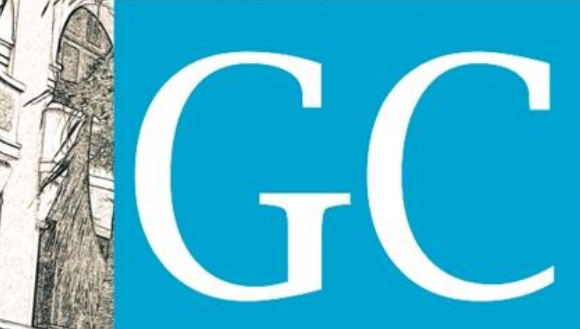

\section{Revista Nacional de}

Gerenciamento de Cidades

O município reformulou o seu Plano Diretor Urbano (PDU) de 1994 em 2006 - Lei 6.705/06 (o primeiro plano diretor data de 1984) e revisou em 2017 (Lei 9.271/2018) com participação dos movimentos sociais, instituições e entidades.

A lei municipal no 5.823 de 30/12/2002 estabeleceu diretrizes e normas da Política Municipal de Habitação (PMH). O município aderiu ao SNHIS em 26/01/2007, criou o FMHIS em 25/04/2008 e o Conselho Municipal de Habitação de Interesse Social (CMHIS). O Plano Local de Habitação de Interesse Social (PLHIS) foi entregue à Caixa Econômica Federal em 28/07/2010. Atualmente o município possui seu PLHIS intitulado Plano Municipal de Habitação e de Regularização Fundiária de Interesse Social, que contém suas linhas de ação, programas, projetos e metas para enfrentar o problema habitacional.

Vitória ostenta excelentes indicadores socioeconômicos, ambientais e tecnológicos: 1ㅇ lugar no país em Bem-Estar Urbano em 2016 (Índice Ibeu 0,9) (GAZETAONLINE, 2016); 2a capital em Índice de Desenvolvimento Humano em 2010 (IDH de 0,845); cidade mais inteligente do país entre municípios com até 500 mil habitantes, concentra 49,84\% do PIB da RMGV e 29,03\% do PIB do Espírito Santo (VITÓRIA EM DADOS, 2019). Porém, a renda per capita possui variações dentro do território municipal em função da história da sua ocupação urbana, que produziu lugares com desigualdades e segregação socioespacial. De acordo com o IBGE (2010) 30,64\% dos domicílios possuem rendimento nominal mensal familiar de até um salário mínimo.

Com uma área territorial de $98.194 \mathrm{~km}^{2}$, Vitória (363.140 habitantes) é o 40 município mais populoso do estado (3.972.388 habitantes) e cidade mais representativa na economia política e econômica da Região Metropolitana da Grande Vitória (RMGV), instituída pela lei estadual no 58/1995 e formada atualmente por sete municípios (Vitória, Vila Velha, Serra, Cariacica, Viana, Guarapari e Fundão), conforme lei complementar no 318/2005 (VITÓRIA EM DADOS, 2018).

A RMGV concentra $48 \%$ da população em $5 \%$ do território e $47,66 \%$ do déficit habitacional (35.532 famílias) do Estado (IJSN, 2017), que ocupa o quarto lugar no país com menor percentual de déficit relativo (8\%) de domicílios (109.535 unidades), o que atinge 222.762 pessoas ( 74.170 famílias). Por outro lado, possui a contradição de ter 171.518 domicílios vagos em condições de serem habitados de um total de 7.906 .767 milhões no país ${ }^{2}$ (FJP, 2018, p. 39).

De acordo com o IJSN (2017), Vitória possui 108.515 domicílios, dentre os quais 26.484 pessoas vivem em domicílios em aglomerados subnormais. Além disso, ocupa o terceiro lugar no Estado no déficit relativo (8,7\%), o que envolve 19.376 pessoas ( 6.345 famílias), conforme tabela 1.

\footnotetext{
${ }^{2}$ A metodologia de cálculo do déficit habitacional adotada no ES é a mesma da Fundação João Pinheiro (FJP), mas estabelece recorte de renda de $1 / 2$ salário mínimo per capita para suas estimativas, com propósito de inserir o foco nas famílias de maior necessidade.
} 


\section{Revista Nacional de}

Tabela 1: Famílias em situação de déficit habitacional no Espírito Santo e Vitória.

\begin{tabular}{lccccc}
\hline Ente & $\begin{array}{c}\text { Habitação precária: } \\
\text { improvisado e rústico }\end{array}$ & $\begin{array}{c}\text { Coabitação: cômodos e } \\
\text { famílias conviventes }\end{array}$ & $\begin{array}{c}\text { Ônus excessivo } \\
\text { com aluguel }\end{array}$ & $\begin{array}{c}\text { Adensamento } \\
\text { excessivo }\end{array}$ & Total \\
\hline Espírito Santo & 5.255 & 821 & 66.427 & 1.667 & 74.170 \\
Vitória & 538 & 41 & 5.699 & 67 & 6.345 \\
\hline
\end{tabular}

Fonte: Elaborado pelos autores (2019) com base nos dados do IJSN (2017) e FJP (2018, p. 31) baseado nos dados das Pesquisas Nacionais por Amostra de Domicílios (PNAD) de 2015 elaboradas pelo IBGE.

Neste âmbito de discussão, este trabalho buscou investigar, analisar e discutir as estratégias, programas, projetos, ações e investimentos da Política de Habitação do município (PHM) de Vitória para o período de 2006 a 2018, definido a partir da regulamentação dos novos programas habitacionais.

\section{METODOLOGIA}

A metodologia englobou consultas á leis municipais sobre a política habitacional, disponíveis no portal da Prefeitura Municipal de Vitória (PMV) na internet e levantamento de dados na própria PMV, através de visitas à Secretaria Municipal de Obras e Habitação (SEMOHAB), sobre a produção habitacional. Para o levantamento de dados sobre recursos financeiros destinados à habitação foram utilizados os Planos Plurianuais (PPAs), as Leis Orçamentárias (LOs) e as Prestações de Contas Anuais (PCAs), compostos por uma série de planilhas e documentos disponibilizados no Portal da Transparência do município na internet.

O Plano Plurianual (PPA) é um instrumento de gestão pública (Federal, Estadual e Municipal) que estabelece para um período de médio prazo (quatro anos) os programas governamentais com seus respectivos objetivos, indicadores, ações orçamentárias e custos da administração para as despesas de capital e outras delas decorrentes, além das relativas aos programas de duração continuada. Sua obrigatoriedade está prevista no artigo 165 da Constituição Federal e regulamentado pelo Decreto 2.829, de 29 de outubro de 1998. Os PPAs da PMV contêm em sua estrutura a descrição dos programas, com seus respectivos objetivos, metas/indicadores, ações orçamentárias, fontes de recursos previstos de custos para a administração pública.

A Lei Orçamentária (LO) estabelece a previsão (estimativa) de despesas municipais durante o período de um ano. No projeto de LO são estabelecidas as prioridades contidas no PPA e as metas que deverão ser atingidas no ano de referência. No valor global de despesas estão incluídos itens tais como: poder legislativo, essenciais à justiça, administração, segurança pública, assistência social, previdência, educação, trabalho, saúde, cultura, direitos da cidadania, habitação, urbanismo, saneamento, gestão ambiental, ciência e tecnologia, comércio e serviços, comunicações, desporto e lazer, encargos especiais e reserva de contingência.

A dotação orçamentária para habitação inclui despesas com construção de unidades, reconstrução e melhorias habitacionais, assim como aquisição de unidades e auxílios diversos (bônus moradia, auxílio moradia, auxílio aluguel) estabelecidos na sua Política Habitacional, através de programas e projetos, vinculados à SEMOHAB.

A receita é composta pela arrecadação de tributos municipais e de outras receitas correntes e 


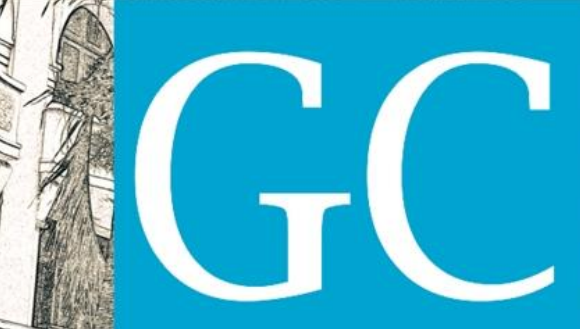

\section{Revista Nacional de}

Gerenciamento de Cidades

de capital. A previsão do valor total da receita é igual ao valor previsto para as despesas. Nesta pesquisa, o levantamento de dados sobre o valor da receita municipal considerou apenas o valor total de receitas correntes somadas às receitas de capital, não considerando déficits e superávits contidos nas planilhas analisadas.

A Prestação de Contas Anual (PCA) é um conjunto de documentos que demonstram a receita anual executada em relação à prevista, além das despesas realizadas para as diferentes funções. Denominado Balanço Orçamentário (BO), é composto por uma série de documentos que comprovam os gastos municipais em relação à receita arrecada. A prestação de contas municipal é divulgada bimestralmente em relatórios resumidos de execução orçamentária.

Nesta pesquisa a PCA foi utilizada com o objetivo de verificar os valores gastos em alguns programas habitacionais específicos, tendo em vista que este trabalho não objetiva comparar os valores para habitação entre os três documentos (PPA, LO e PCA), mas avaliar os valores anualmente previstos nos PPAs e nas LOs; além de utilizar as PCAs para identificar os recursos financeiros gastos com as formas de provisão da moradia (construção, melhorias, auxílio aluguel, etc).

A justificativa decorre do fato do PPA englobar a previsão de despesas e receitas por programas e projetos; já a LO é organizada por funções (habitação, saneamento, urbanização, etc) e a PCA contém, além de funções, programas e projetos. Comparar a função "habitação" entre os documentos pode levar a um erro, tendo em vista que itens tais como urbanismo e saneamento, previstos nos PPAs para alguns projetos habitacionais podem estar separados nas Leis Orçamentárias (Saneamento e Urbanismo), o que gera impacto na redução da função "habitação".

Os resultados foram organizados em planilhas, expressos em gráficos e mapas. Contribuem como um diagnóstico que demonstra como o município de Vitória, com seus excelentes indicadores sociais e econômicos, tem buscado solucionar o acesso à moradia das populações mais pobres e atender às diretrizes e preceitos sobre planos e planejamento urbano, estabelecidas no Estatuto da Cidade.

\section{RESULTADOS}

\subsection{POLÍTICA MUNICIPAL DE HABITAÇÃO (PMH)}

A Secretaria Municipal de Habitação e Obras - SEMOHAB é o órgão responsável pela execução da $\mathrm{PMH}$, que entrou em vigor a partir de 2002 e possui como marcos legais relevantes para este estudo, as leis municipais no 5.823 de 30/12/2002, № 6.592 de 03/05/2006 e no 6.967 de 21/06/2007.

A lei 5.823/2002 estabeleceu diretrizes e normas da Política Municipal de Habitação (PMH), criou o Conselho Municipal de Habitação de Interesse Social - CMHIS, o Fundo Municipal de Habitação de Interesse Social - FMHIS, definiu as formas de acesso à moradia e criou a Secretaria Especial de Habitação, depois transformada em Secretaria Municipal de Habitação e Obras. 


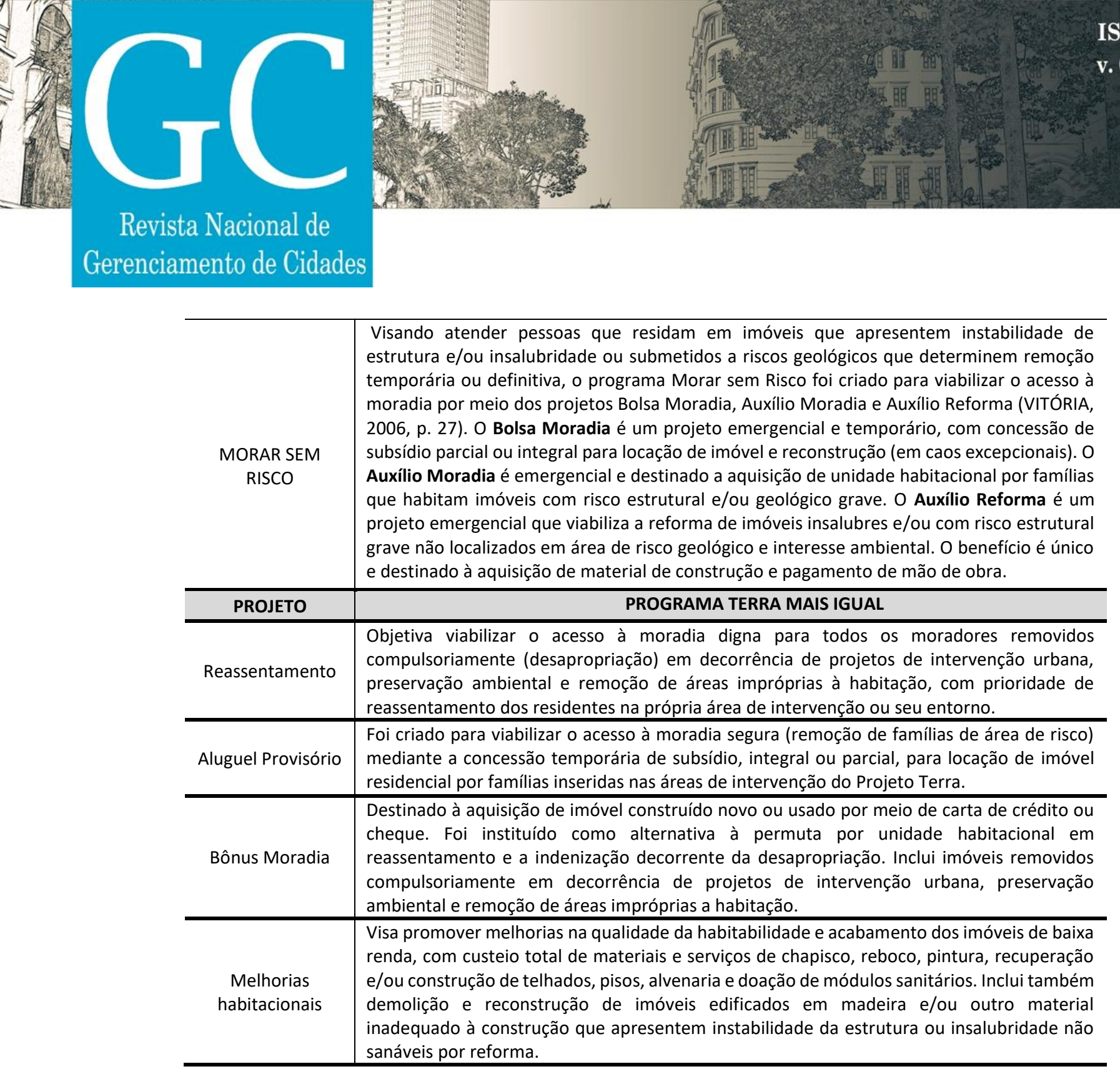

Fonte: Elaborado pelos autores (2018) com base nas leis municipais no 6.592/2006 e no 6.967/2007.

O Projeto Terra foi criado pelo Decreto no 10.131 de 14/01/1998, o Programa Integrado de Desenvolvimento Social, Urbano e de Preservação Ambiental nas Áreas Ocupadas por População de Baixa Renda no Município de Vitória - Projeto Terra, renomeado pelo Decreto no 13.669 de 28/12/2007 como Projeto Terra Mais Igual, objetiva promover a melhoria da qualidade de vida da população socialmente excluída, efetuando seu empoderamento através de um conjunto integrado de ações sociais, obras e serviços de natureza pública, que viabilizem as mesmas condições de acesso aos bens e serviços públicos das demais áreas do município (Art.1으 Decreto 13.669/2007).

Destinado a famílias com renda até 3 (três) salários mínimos ou renda familiar per capita menor ou igual a $1 / 2$ (meio) salário mínimo. O programa atua nos territórios das Poligonais (quinze áreas da capital caracterizadas com riscos sociais, físicos e ambientais).

Destaca-se que o município implantou o Projeto Moradias Alternativas no âmbito do Projeto Morar sem Risco, destinado aos moradores em situação de rua, que podem receber como benefícios o aluguel social no valor de até um salário mínimo para custear a moradia que escolher e uma carta de crédito no valor de $\mathrm{R} \$ 60$ mil para adquirir uma nova moradia. Para ter 

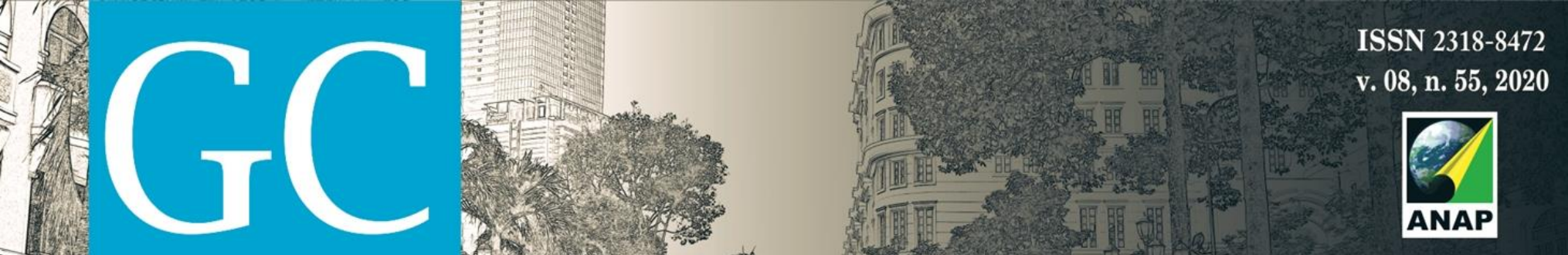

\section{Revista Nacional de}

Gerenciamento de Cidades

acesso ao benefício o morador em situação de rua deve possuir mais de um ano nos abrigos da capital e passar por uma triagem envolvendo todas as secretarias.

Visando identificar onde as ações dos programas Habitar Vitória e Terra Mais Igual estão distribuídas no território, a pesquisa elaborou dois mapas, com base nos dados fornecidos pela PMV (Figuras 1 e 2). As ações englobam em maior número reformas, reconstruções, melhorias habitacionais e regularização fundiária.

A tabela 3 mostra a quantidade de intervenções realizadas. Os números demonstram que as ações estão voltadas à solução do problema habitacional relacionado à precariedade das moradias, assim como problemas decorrentes da ocupação em assentamentos subnormais e à autoconstrução. Verifica-se que a soma de intervenções executadas, excluindo a construção de módulos hidráulicos e a regularização fundiária (emissão de escrituras) totalizam 4.496 unidades, sendo a maioria de reformas, melhorias e reconstruções, com total de 3.682 unidades.

Figura 1. Mapa do município de Vitória contendo a localização das ações do Programa Habitar Vitória.

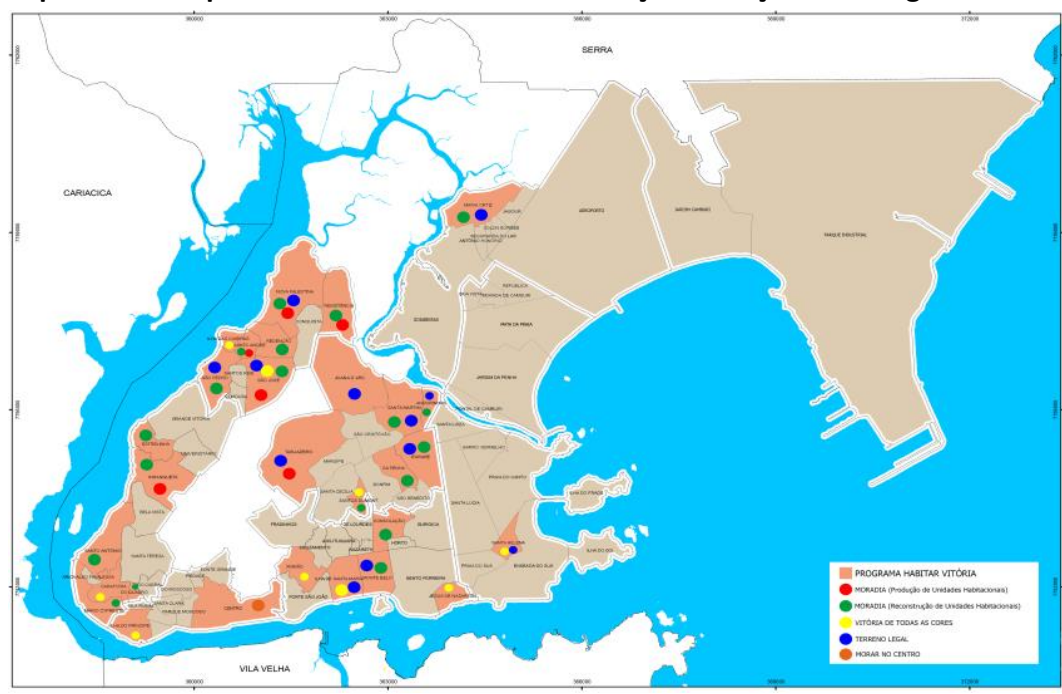

Fonte: Elaborado pelos autores, 2018. 


\section{Revista Nacional de}

Gerenciamento de Cidades

invadindo áreas, ocupando terrenos em loteamentos irregulares ou clandestinos e, autoconstruindo a moradia, forma típica de morar no início da década de 1980.

Duarte (2008, p. 162) em sua pesquisa sobre a relação da expansão das periferias na RMGV com a implantação dos conjuntos habitacionais construídos pelo SFH/BNH no período de 1964 a 1986, destaca que o movimento migratório, a especulação imobiliária, o desemprego, a ausência de políticas sociais eficientes e a própria política habitacional vigente, contribuíram para a pobreza e a precarização da moradia. Relatório ${ }^{3}$ do IJSN de 1987 sobre a situação habitacional na RMGV ressalta a ineficiência da COHAB-ES em resolver os problemas, beneficiando as parcelas de maior renda.

\subsection{RECURSOS FINANCEIROS PARA EXECUÇÃO DA PMH}

Para investigar e analisar os recursos financeiros da dotação orçamentária destinados aos programas e projetos da PMH de 2006 a 2018, a pesquisa consultou os Planos Plurianuais (PPA), as Leis Orçamentárias (LOs) e as planilhas de Prestação de Contas Anuais (PCAs) disponíveis no Portal da Transparência da PMV. Os programas indicados para Habitação previstos nos PPAs estão descritos na tabela 4, conforme documentos avaliados, com seus respectivos programas e ações.

Tabela 4. Investimentos previstos nos Planos Plurianuais para os programas e projetos habitacionais.

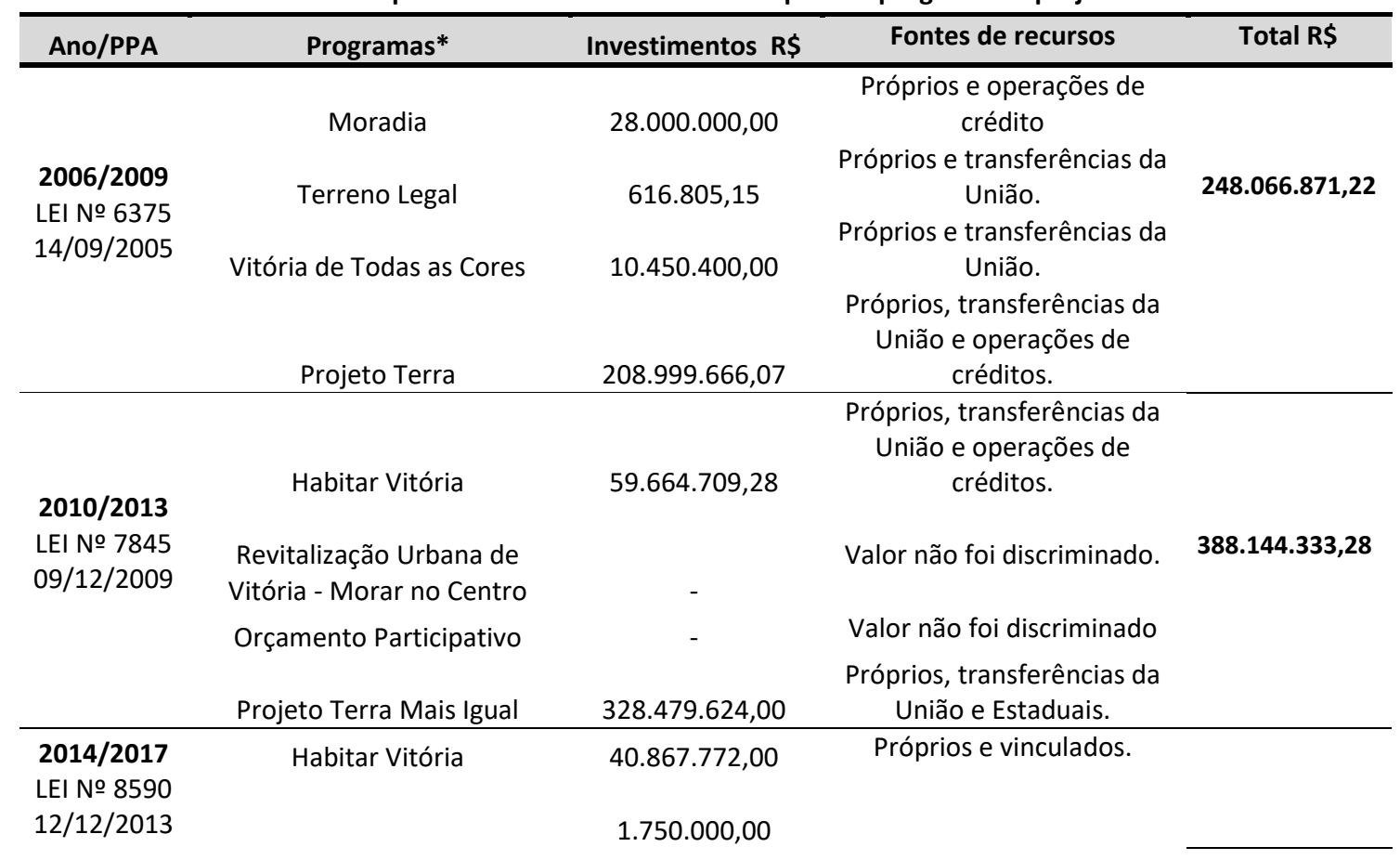

\footnotetext{
3 Dados do IJSN de 1987 destacam que das 950 mil pessoas que viviam na RMGV (formada por cinco municípios à época) cerca de 400 mil moravam em condições subnormais em 179 assentamentos precários; destes, 47 estavam localizados na capital. As invasões de terras e ocupações de obras inacabadas da COHAB-ES foram consequências desta situação de exclusão.
} 


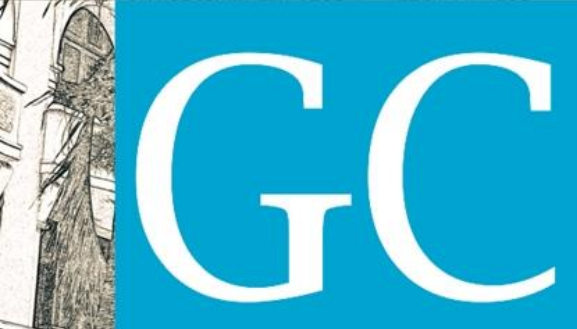

\section{Revista Nacional de}

Gerenciamento de Cidades

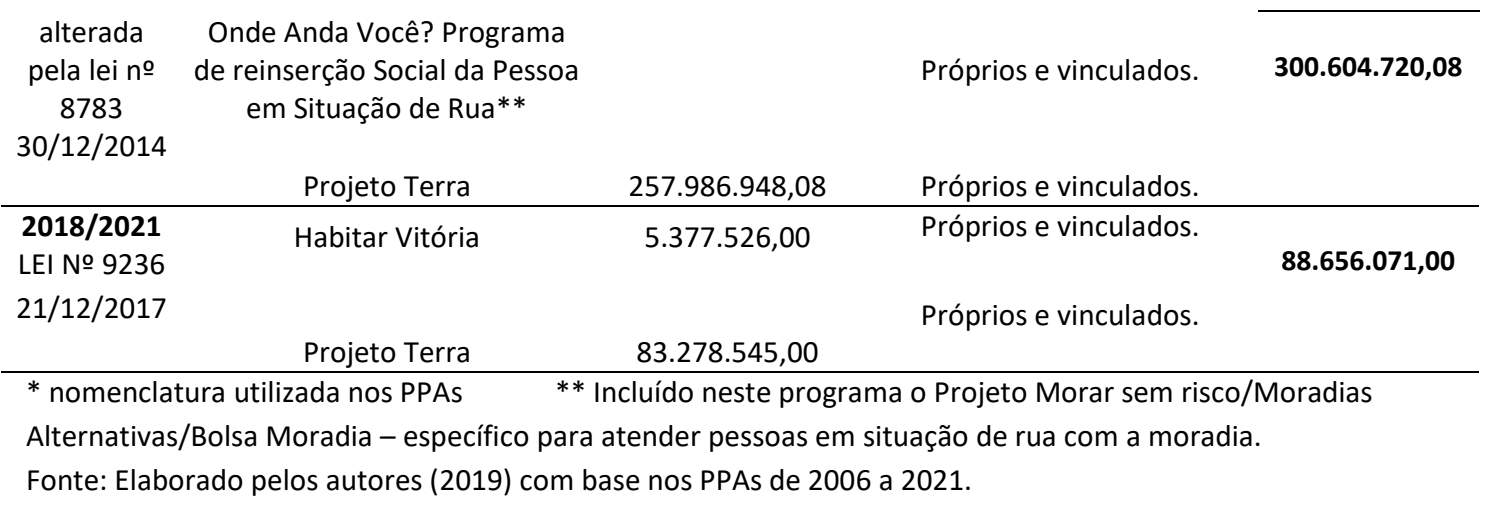

No PPA de 2006-2009 foram identificados investimentos previstos em habitação em quatro programas, com ações orçamentárias que englobam construção de unidades habitacionais, titulação em áreas irregulares, melhorias sanitárias domiciliares (banheiro construído), melhorias habitacionais, regularização fundiária, projetos de urbanização e desenvolvimento social. O valor total previsto foi de $\mathrm{R} \$ 248.066 .871,22$.

No PPA de 2010-2013 as ações orçamentárias que contemplam a habitação estiveram presentes em dois programas, o Habitar Vitória (engloba os projetos Moradia, Vitória de Todas as Cores, Terreno Legal, Morar sem Risco (bolsa moradia e auxílio moradia) e o Terra Mais Igual (aluguel provisório, bônus moradia, intervenções habitacionais, regularização fundiária, projetos de urbanização, desenvolvimento social) totalizando $\mathrm{R} \$ 388.144 .333,28$.

Outros dois programas também contemplavam ações orçamentárias para habitação. 0 programa Revitalização Urbana de Vitória incluía o Morar no Centro com a construção de unidades e o Orçamento Participativo com construção de novas unidades, reconstrução e melhorias, reforma e/ou construção de banheiros e regularização fundiária de interesse social no âmbito do projeto Terreno Legal. No entanto, no valor global dos programas, não foi identificado o valor específico destinado à habitação.

Verifica-se que desde 2006 os programas habitacionais tiveram previsão de investimentos no

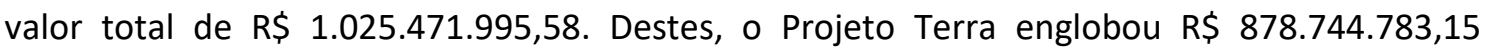
$(85,69 \%)$ em ações destinadas às Poligonais. Comparando a previsão por período, verifica-se que houve uma queda significativa de investimentos nos programas habitacionais, com destaque para os períodos de 2014 a 2021, que juntos somam $\mathrm{R} \$ 389.260 .791,08$, o que representa uma redução de aproximadamente 39\% em relação ao período de 2006 a 2013, com investimentos totais de $\mathrm{R} \$ \mathbf{6 3 6 . 2 1 1 . 2 0 4 , 5 0 .}$

No PPA de 2014-2017, além das ações orçamentárias para os programas Habitar Vitória e Terra, foram previstos investimentos em habitação no programa "Onde você anda? Programa de Reinserção Social da Pessoa em Situação de Rua", que além de atendimento social, incluiu a moradia como instrumento de inclusão social através do Projeto Morar sem Risco (Moradias alternativas/Auxílio Moradia/Bolsa Moradia), com um montante especificado de $\mathrm{R} \$$ $1.750 .000,00$. 


\section{Revista Nacional de}

Gerenciamento de Cidades

No PPA 2018-2021 as ações orçamentárias previstas em habitação totalizam R\$ 88.656.071,00 destinados aos programas Habitar Vitória e Projeto Terra. Este PPA despertou atenção especial da pesquisa, tendo em vista a redução considerável de investimentos previstos para habitação, quando comparados com os PPAs anteriores. Comparado ao PPA 2014-2017 houve uma redução de $70,51 \%$ nas ações orçamentárias previstas.

Sobre as despesas previstas para habitação nas Leis Orçamentárias (LOs) de 2006 a 2018, os dados foram organizados, conforme tabela 5 a seguir. Nota-se que o percentual relativo entre despesas previstas em habitação e despesas totais do município variam entre 0,63\% (2018) e 4,74\% (2008), não ultrapassando 5\%. Em 2008, o crescimento previsto para a receita foi de $21,99 \%$ e o percentual destinado à habitação foi de $4,74 \%$, representando um crescimento de $78,78 \%$ em relação ao ano anterior (2007). Porém, no ano de 2012 , a variação da receita prevista decresceu $0,21 \%$ em relação a 2011 e a habitação teve redução de $22,25 \%$. Além disso, a soma de investimentos previstos para habitação de 2006 a 2018 equivale a somente $2,85 \%$ de toda receita do município ( $\mathrm{R} \$ 18.738 .800 .479,08)$.

Nos anos de 2016 e 2017 houve evolução negativa do crescimento da receita prevista e dos investimentos em habitação (-54,43\% e $-28,63 \%$ respectivamente). Para 2018 , a previsão de crescimento para a receita foi de $5,04 \%$ receita, mas com recursos reduzidos para habitação (-44,02\%) em relação a 2017.

Tabela 5. Previsão de receitas e despesas para habitação conforme Leis Orçamentárias de 2006 a 2018.

\begin{tabular}{|c|c|c|c|c|c|c|c|}
\hline \multirow[b]{2}{*}{ ANO } & \multirow[t]{2}{*}{ Leis Orç. } & \multicolumn{2}{|c|}{ RECEITA/DESPESA } & \multicolumn{4}{|c|}{ HABITAÇÃO } \\
\hline & & Total R\$ & $\begin{array}{c}\% \\
\text { variação } \\
\text { anual }\end{array}$ & $\begin{array}{l}\text { Total } \mathbf{R} \mathbf{S} \\
\text { previsto }\end{array}$ & $\begin{array}{l}\% \text { relativo } \\
\text { receita/desp. }\end{array}$ & $\begin{array}{c}\% \\
\text { variação } \\
\text { anual }\end{array}$ & Total R\$ \\
\hline 2006 & $6465 / 2006$ & $794.875 .120,08$ & $21,21 \%$ & $21.224 .513,69$ & $2,67 \%$ & $3,65 \%$ & \\
\hline 2007 & $6793 / 2006$ & $967.994 .913,00$ & $21,78 \%$ & $31.319 .135,00$ & $3,24 \%$ & $47,56 \%$ & $161.946 .526,69$ \\
\hline 2008 & $7123 / 2007$ & $1.180 .839 .718,00$ & $21,99 \%$ & $55.993 .228,00$ & $4,74 \%$ & $78,78 \%$ & \\
\hline 2009 & $7633 / 2008$ & 1.287.765.530,00 & $9,06 \%$ & $53.409 .650,00$ & $4,15 \%$ & $-4,61 \%$ & \\
\hline 2010 & $7847 / 2009$ & $1.399 .356 .339,00$ & $8,67 \%$ & $57.809 .174,49$ & $4,13 \%$ & $8,24 \%$ & \\
\hline 2011 & $8013 / 2010$ & $1.573 .891 .486,00$ & $12,47 \%$ & $56.913 .840,00$ & $3,62 \%$ & $-1,55 \%$ & $211.341 .594,49$ \\
\hline 2012 & $8202 / 2011$ & $1.570 .645 .605,00$ & $-0,21 \%$ & $44.248 .000,00$ & $2,82 \%$ & $-22,25 \%$ & \\
\hline 2013 & $8397 / 2012$ & 1.652.165.400,00 & $5,19 \%$ & $52.370 .580,00$ & $3,17 \%$ & $18,36 \%$ & \\
\hline 2014 & $8591 / 2013$ & $1.820 .606 .500,00$ & $10,20 \%$ & $53.945 .300,00$ & $2,96 \%$ & $3,01 \%$ & \\
\hline 2015 & $7633 / 2014$ & $1.867 .035 .400,00$ & $2,55 \%$ & $54.183 .455,00$ & $2,90 \%$ & $0,44 \%$ & $150.445 .439,00$ \\
\hline 2016 & $8912 / 2016$ & $1.572 .652 .529,00$ & $-15,77 \%$ & $24.693 .809,00$ & $1,57 \%$ & $-54,43 \%$ & \\
\hline 2017 & $9050 / 2016$ & 1.488.022.391,00 & $-5,38 \%$ & $17.622 .875,00$ & $1,18 \%$ & $-28,63 \%$ & \\
\hline 2018 & $9237 / 2017$ & $1.562 .949 .548,00$ & $5,04 \%$ & $9.864 .781,00$ & $0,63 \%$ & $-44,02 \%$ & $9.864 .781,00$ \\
\hline \multicolumn{2}{|c|}{ Total - R\$ } & $18.738 .800 .479,08$ & & $533.598 .341,18$ & $2,85 \%$ & & $533.598 .341,18$ \\
\hline
\end{tabular}

Fonte: Elaborado pelos autores, 2019.

O gráfico da figura 3 expressa a relação entre a variação percentual anual da receita prevista e a variação percentual anual dos investimentos previstos para habitação. Destaca-se que no período de 2006 a 2018 houve crescimento da receita prevista para o município, porém as despesas destinadas à habitação sofreram queda acentuada, principalmente nos últimos quatro 


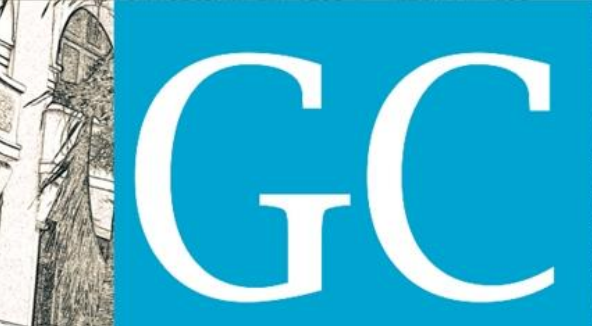

\section{Revista Nacional de}

\section{Gerenciamento de Cidades}

anos.

Figura 3. Gráfico mostra variação anual do \% de investimentos previstos para habitação em relação à variação anual dos percentuais relativos às despesas/receitas previstas nas LOs de 2006 a 2018.

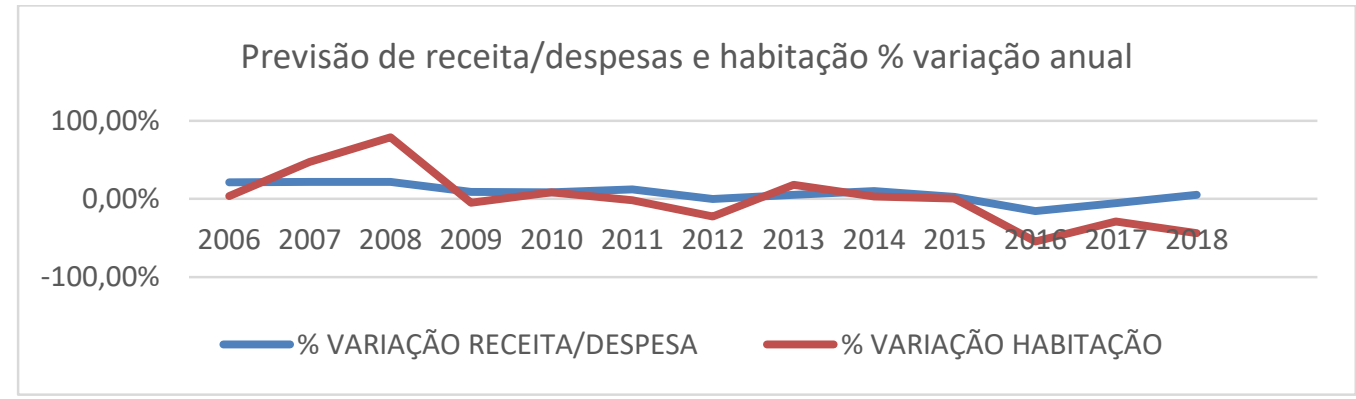

Fonte: Elaborado pelos autores, 2019.

Durante a pesquisa um dado que levantou atenção nas Planilhas de Prestação de Contas Anuais (PCAs) foram os recursos financeiros utilizados para aluguel provisório (o beneficiário recebe um valor financeiro para locar uma moradia no município de Vitória), tendo em vista que na pesquisa de campo na SEMOHAB foram ouvidos relatos sobre o grande número de famílias que recebem este auxílio para locação de uma moradia. Destaca-se que o auxílio aluguel representa um problema para o Poder Público, primeiro quanto à gestão das famílias nesta situação; segundo, porque consome recursos que poderiam ser destinados a outros projetos, tais como produção de novas unidades, reformas e melhorias habitacionais, principalmente readequações de edifícios na área central.

Neste sentido, a pesquisa realizou um levantamento dos valores destinados a este tipo de benefício provisório e comparou com a construção de unidades habitacionais (Projeto Moradia, Orçamento Participativo e Fundo Municipal de Habitação de Interesse Social); melhorias, reconstruções e intervenções habitacionais (Projeto Moradia, Vitória de Todas as Cores, Programa Terra, Orçamento Participativo e Fundo Municipal de Habitação de Interesse Social); e os investimentos direcionados para requalificação de edifícios (Projeto Morar no Centro).

O recorte temporal foi o período de 2013 a 2018, tendo em vista que as planilhas de PCAs disponíveis no Portal da Transparência do município detalham os valores gastos por programa e projeto, o que não foi identificado nas planilhas de 2006 a 2012. Os dados obtidos estão detalhados na tabela 6 a seguir. 


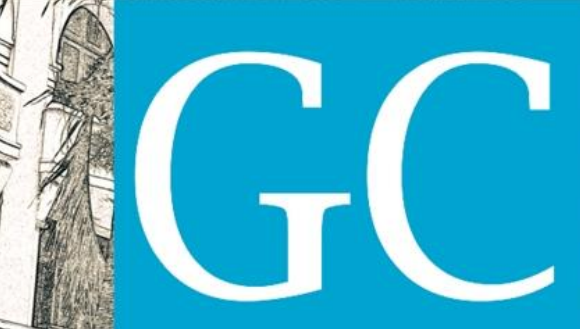

\section{Revista Nacional de}

direito à moradia e o cumprimento da função social da propriedade (SÉCULO DIÁRIO, 2019), em uma região com mais de cem prédios ociosos e vazios, conforme mapeamento realizado pela Associação de Moradores do Centro da capital (SIMNOTíCIAS, 2018).

Segundo dados divulgados em 2018 pelo Movimento Nacional das Famílias Sem-Teto, cerca de 100 pessoas ocupavam seis imóveis (cinco edifícios e uma casa) na região central da capital. Dos imóveis ocupados, três são de responsabilidade da prefeitura e os demais de propriedade particular, sendo que um dos edifícios já está incluído no programa social de habitação e aguarda reforma (GAZETAONLINE, 2018). Destaca-se que as ocupações expressam um problema não resolvido há décadas em todo país, que diferentes políticas habitacionais não conseguem solucionar: o acesso dos mais pobres à moradia.

As ocupações de edifícios em áreas centrais representam a forma das famílias reivindicarem este direito, estabelecido na Constituição Federal (1988) e na Declaração Universal de Direitos Humanos (1948). O impasse continua.

\section{CONCLUSÃO}

Para combater a problemática habitacional, a capital capixaba desenvolve sua Política Habitacional baseada em dois programas denominados Projeto Terra Mais Igual e Habitar Vitória, cujas ações se desenvolvem por meio de doze projetos habitacionais que contemplam construção de novas unidades, melhorias habitacionais, auxílio moradia, dentre outros.

Nos últimos 12 anos, as estratégias e ações da prefeitura para mitigar os problemas habitacionais referem-se à produção de novas unidades, melhorias habitacionais e auxílios moradia, com investimentos previstos em Planos Plurianuais e Leis Orçamentárias. No entanto, com poucos impactos na redução do déficit habitacional. Dados demonstram que Vitória detinha em 2000 uma população de 292.304 habitantes e déficit habitacional absoluto de 6.045 unidades. Nos últimos 18 anos houve um aumento da população em 24,23\% (363.140 habitantes) e do déficit habitacional absoluto de 5\% aproximadamente, com 6.345 famílias em situação de déficit (IJSN, 2017).

\section{REFERÊNCIAS BIBLIOGRÁFICAS}

IBGE. Censo Demográfico 2010. Disponível em <https://sidra.ibge.gov.br/pesquisa/censo-demografico/demografico2010/universo-caracteristicas-da-populacao-e-dos-domicilios> Acesso em 10 abril 2018.

BONDUKI, Nabil. Os pioneiros da habitação social no Brasil: volume 1. 1a edição. São Paulo: editora Unesp - edições Sesc, 2014. 387 pag.

DUARTE, Maurizete Pimentel Loureiro. A expansão da periferia por conjuntos habitacionais na Região da Grande Vitória (1964-1986). Dissertação de Mestrado. Programa de Pós-graduação em História Social das Relações Políticas do Centro de Ciências Humanas e Naturais. Universidade Federal do Espírito Santo, 2008. 237p.

FJP (FUNDAÇÃO JOÃO PINHEIRO). Centro de Estatística e Informações. Déficit habitacional no Brasil 2015. Belo Horizonte, 2018. Disponível em <http://www.fjp.mg.gov.br/index.php/docman/direi-2018/estatistica-e- 


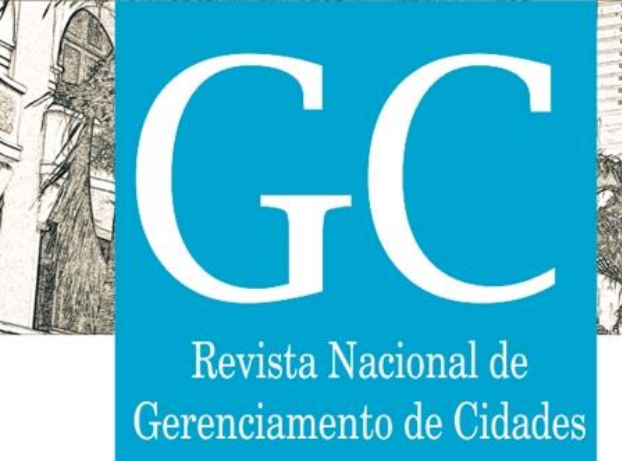

informacoes/797-6-serie-estatistica-e-informacoes-deficit-habitacional-no-brasil-2015/file > Acesso em: 27 dez.2017.

GAZETAONLINE. Vitória aparece em 10 lugar entre as capitais em ranking de bem-estar urbano. Disponível em <https://www.gazetaonline.com.br/noticias/cidades/2016/09/vitoria-aparece-em-1-lugar-entre-as-capitais-emranking-de-bem-estar-urbano-1013980247.html> Acesso em: 23 maio 2018.

Atualmente, 800 pessoas vivem em situação de rua na Grande Vitória. 2019. Disponível em <https://www.gazetaonline.com.br/noticias/cidades/2019/06/atualmente-800-pessoas-vivem-em-situacao-de-ruana-grande-vitoria-1014187288.html>. Acesso em: 15 de julho de 2019.

100 pessoas ocupam prédios abandonados no Centro de Vitória. 2018. Disponível em < https://www.gazetaonline.com.br/noticias/cidades/2018/05/100-pessoas-ocupam-predios-abandonados-emvitoria-1014129424.html>. Acesso em: 18 de julho de 2019.

IJSN. Plano Emergencial de Habitação - Grande Vitória. Grupo de Trabalho do Governo Estadual para definição de Política Habitacional, $1987 . \quad$ Disponível $\quad$ em <http://www.ijsn.es.gov.br/ConteudoDigital/20120810_ij00436_planoemergencialdehabitacao.pdf> Acesso em: 09/09/2019.

IJSN. Déficit Habitacional no Espírito Santo com base no Cadúnico 2017. Disponível em <http://www.ijsn.es.gov.br/ConteúdoDigital/20160905_ij01431_deficit_habitacional_2016.pdf> Acesso em: 14 maio 2018.

MIRANDA, Clara Luiza; ABE, André Tomoyuki; HENRIQUES, Michele Pereira Paes; COELHO, Margareth Batista Saraiva. Marcos Legais e regulatórios da urbanização e das zonas de especial interesse social em Vitória - ES, Brasil. In: Desafios para a habitação de interesse social: Território do Bem / Miriam de Magdala Pinto (org.). - Dados eletrônicos. - Vitória, ES: UFES, LabTAR, 2017.

SÉCULO DIÁRIO. Movimento de moradia e prefeitura seguem em impasse sobre Edifício Santa Cecília. 2019. Disponível em <https://seculodiario.com.br/public/jornal/materia/movimento-de-moradia-e-prefeitura-seguemem-impasse-sobre-edificio-santa-cecilia>. Acesso em: 28 de junhde 2019.

SIMNOTÍCIAS. Mais de cem prédios estão abandonados no Centro de Vitória. 2018 Disponível em <https://www.simnoticias.com.br/mais-de-cem-predios-estao-abandonados-no-centro-de-vitoria/>. Acesso em: 10 de maio de 2019.

VITÓRIA. Lei 5.823/2002. Disponível em <http://sistemas.vitoria.es.gov.br/webleis/>. Acesso em: 15 jun. 2018.

Lei 6.592/2006. Disponível em < http://sistemas.vitoria.es.gov.br/webleis/>. Acesso em: 15 jun. 2018.

Lei 6.967/2007. Disponível em < http://sistemas.vitoria.es.gov.br/webleis/>. Acesso em: 15 jun. 2018. $\overline{2019 .}$

VITÓRIA EM DADOS. Disponível em < http://legado.vitoria.es.gov.br/regionais/home.asp >. Acesso em: 30 jun.

TRANSPARÊNCIA VITÓRIA. Disponível em <http://transparencia.vitoria.es.gov.br/>. Acesso em 23 de maio de 2019. 